\title{
ANALISIS KUALITAS PELAYANAN, CITRA MERK, KEPERCAYAAN TERHADAP KEPUASAN KONSUMEN JASA GO-JEK UNIVERSITAS ISLAM BATIK SURAKARTA
}

\author{
Sutardi $^{1 *}$, Bambang Mursito ${ }^{2)}$, Rochmi Widayanti ${ }^{3)}$ \\ Program Studi Manajemen, UniversitasIslam Batik Surakarta Jl. KH. Agus Salim No.10 Surakarta \\ Email :ardian57@gmail.com
}

\begin{abstract}
Consumer satisfaction is online media in terms of service quality, brand image and trust in Gojek service users at Surakarta Batik Islamic University. Description, This study aims to determine the effect of both simultaneous and partial service quality, brand image and trust in customer satisfaction at Go-jek service users at the Islamic Batik University of Surakarta, Quantitative descriptive analysis, the population is 1,020, the sample used is 102 respondents. Purposive sampling technique, analysis technique using statistical analysis.The results of the study show that the F test of service quality, brand image and trust simultaneously and significantly influence consumer satisfaction in Go-jek service users at the Islamic Batik University of Surakarta. The results of the t test show that service quality, brand image and all trust have a positive and significan effect on consumer satisfaction in Gojek service users at the Islamic Batik University of Surakarta. The model used multiple linear regression, In the equation of this study is $Y=1.538+0.171+0.463+0.288+e$. the results of thehcoefficient of determination show the quality of service, brand image and trust has an influence of $56.5 \%$ on customer satisfaction in Go-jek service users at the Islamic Batik University of Surakarta.
\end{abstract}

Keywords: customer satisfaction, service quality, brand image, trust

\section{PENDAHULUAN}

Perkembangan teknologi dan informasi Internet (E-Commerce) merupakan teknologi baru yang dapat menjadi suatu bisnis yang menjanjikan di Indonesia, adanya teknologi internet (E-Commerce) perusahaan Go-Jek mampu memanfaatkan dengan baik, munculnya teknologi internet perusahaan Go-jek bisa memberikan kemudahan bagi masyarakat di bidang transportrasi untuk menunjang kegiatan sehari-hari dalam memenuhi kebutuhan masyarakat. Dalam hal ini persaingan bisnis diIndonesia dibidang teknologi/ internet semakin ketat suatu hal yang menjadikan prioritas sebuah perusahaan adalah kepuasan konsumen. (Khairunissa, Suharyono dan Yulianto, 2017).

Salah satu tujuan Go-jek adalah memberikan jasa untuk memenuhi kebutuhan dan keinginan masyarakat dibidang transpotasi, dengan adanya transpotasi online masyarakat lebih mudah melakukan kegiatan sehari-hari, sehingga masyarakat puas dalam menggunakan jasa Gojek, apabila pengguna Go-jek puas maka terjadilah pelanggan yang loyalitas sehingga pengguna jasa Go-jek akan memakai jasa tersebut dan melakukan pembelian ulang kembali, penelitian ini juga diperkuat oleh (Mar'ati, 2016).

Adanya kualitas pelayanan yang diberikan Go-jek sesuai harapan dan keinginan konsumen, maka akan meningkatkan kepuasan konsumen dalam menggunakan jasa Go-jek, sehingga apabila konsumen tidak merasa puas dan tidak sesuia harapan maka akan 
merugikan perusahaan Go-jek itu sendiri, maka itu perusahaan Go-jek untuk meningkatkan kualitas pelayanan serta kepercayaan agar pengguna jasa Go-jek puas dalam memakai jasa tersebut (Anggraeni dan Karmilasari, 2017). Menjelasakan bahwa kualitas layanan secara silmutan berpengaruh positif dan signifikan terhadap kepuasan konsumen.

Citra merk perusahaan dalam hal ini juga diperlukan karena suatu jasa atau produk yang dihasilakan bisa dilihat berdasarkan pengideraan dari objek-objek fisik maupun social tergantung pada stimulus dilingkungannya, Menurut (Rizan, Yulianti dan Rahmi, 2015). Menyatkan bahwa citra merk berpengaruh positif dan signifikan terhadap kepuasan konsumen.

Dalam memberikan kepuasan konsumen maka kepercayaan juga hari diperhatikan karena kepercayaan konsumen merupakan kemauan untuk mempercayai merk dengan segala resikonya, karena adanya harapan merek tersebut dapat memberikanh hasil yang positif. Kepercayaan yang timbul dari konsumen atas produk yang diberikan perusahaan mempengaruhi perilaku konsumen untuk memilih atau melakukan keputusan pembelian yang akan berlanjut pada loyalitas konsumen. Menurut (Wijaya dan Kempa, 2018) juga menjelaskan bahwa variabel kepercayaan berpengaruh positif dan signifikan terhadap kepuasan konsumen

Berdasarkan wawancara pada beberapa penggunaan layanan Go-jek di Universitas Islam Batik Surakarta memberikan arahan bahwa pengguna Go-jek lebih puas apabila tingkat keaman dan kenyamana lebih di utamakan karena apabila pengguna Go-jek nyaman dan aman maka pembelian ulang dan loyalitas pelanggan akan terjalin harmonis serta pelanggan Go-jek akan melakukan pembelian ulang kembali. Berdasarkan latar belakang diatas maka penulis berpendapat untuk menadakan penelitian tentang Analisis Kualitas Pelayanan, Citra Merk, Kepercayaan Terhadap Kepuasan konsumen pengguna jasa Go-jek di Universitas Islam Batik Surakarta.

\section{KAJIAN TEORI}

Pada dasarnya tujuan dari suatu bisnis adalah untuk menciptakan konsumen merasa puas, terciptanya kepuasan konsumen dapat memberikan beberapa manfaat antara lain pengaruh antara perusahaan dan konsumen menjadi harmonis, memberikan da sar yang baik bagi pembelian ulang dan terciptanya loyalitas konsumen. kepuasan atau ketidak puasan konsumen adalah respon konsumen terhadap evaluasi ketidaksesuaian i(disconfirmation) yang dirasakan antara harapan sebelumnya dan kinerja aktual produk yang dirasakan setelah pemakaiannya.Menuruti (Lovelock dan Wirtz, 2011:74) Kepuasan adalah suatu sikap yang diputuskan berdasarkan pengalaman y ang didapatkan, defenisi ini juga diperkuat (Kiswara, 2017). mendefinisikan kepuasan pelanggan sebagai sikap keseluruhan terhadap suatu barang atau jasa setelah di peroleh (acquition) dan Dengan kata lain, kepuasan pelanggan merupakan penilaiaan evaluative purnabeli yang dihasilkan dari seleksi pembeliaan.

Kualitas layanan adalah suatu kondisi dinamis yang berhubungan dengan produk, tenaga kerja, proses dan tugas, serta lingkungan untuk memenuhi kebutuhan atau harapan konsumen, Dalam hal ini Kualitas layanan diwujudkan untuk pemenuhan kebutuhan dan keinginan pelanggan serta ketetapan penyampaiannya dalam mengimbangi atau melampaui harapan pelanggan.Menurut (Adam 2015:12) Tiga faktor yang dapat 
mempengaruhi harapan seseorang dalam mengkonsumsi pelayanan jasa adalah informasi langsung, kebutuhan seseorang dan pengalaman.

Citra merk adalah sejenis asosiasi yang muncul dibenak konsumen ketika mengingat sebuah merk tertentu, Seringkali nama merek tertentu yang muncul pertama kali dibenak konsumen karena konsumen memiliki persepsi bahwa merk tersebut terasosiasi dengan pemenuhan kebutuhan dan keinginan konsumen. Menurut (Tjiptono, 2011:112). Citra merk adalah deskripsi tentang asosiasi dan keyakinan konsumen terhadap merk tertentu. Sedangkan Menurut (Kotler dan Keller, 2016), merk adalah sebuah nama, istilah, tanda, lambang, desain atau kombinasinya yang untuk mengidentifikasikan barang atau jasa dari salah satu penjual atau kelompok penjual dan mendefinisikan mereka dari para pesaing.

Menurut (Kotler, 2009:219) Menjelaskan bahwa kepercayaan adalah kesediaan perusahaan untuk bergantung pada mitra bisnis sedangkan menurut (Turban,2010:199) juga mendefinisikan bahwakepercayaan yaitu melibatkan adanya kesediaan seorang agar memiliki keyakinan bahwa rekan kerjanya akan memberikan kualitas pelayanan yang baik serta produk yang di hasilkan seperti yang di inginkan kon sumenya serta kata janji atau pernyataan seseorang dapat dipercaya oleh konsumenya.

\section{METODOLOGI PENELITIAN}

Penelitian ini menggunakan pendekatan deskriptif kuantitatif. Lokasi yang diteliti di Universitas iIslam Batik Surakarta. Populasi yang diambil dibidang manajemen siang dan malam yang berjumlah 1.020 dan menggunakan contoh sampel sebanyak 102 responden, teknik pengambilanya dengan mengambil sampel 10\% dari Menurut (Suharsimi Arikunto, 2010:134).

\section{HASIL PENELITIAN DAN PEMBAHASAN}

\section{Uji Asumsi Klasik}

\section{Hasil Uji Normalitas}

Hasil uji normalitas menggunka analisis Kolmogorov - Smirnov test, hasil bisa dilihat pada tabel dibawah ini :

\section{Tabel 1}

Hasil Uji Normalitas

\begin{tabular}{ccccc}
\hline Variabel & $\begin{array}{c}\text { Kolmogorov- } \\
\text { Smirnov Test }\end{array}$ & Sign & Probabilitas & Kesimpulan \\
\hline Asymp. & 0,785 & 0,568 & $>0,05$ & $\begin{array}{c}\text { Dataterdistribu } \\
\text { Si normal } \\
\text { Tailed) }\end{array}$ \\
\hline
\end{tabular}

Hasil pengujian menunjukkan Asymp. Sig. (2-tailed) (0,568) >0,05, artinya persamaan regresi memiliki sebaran data yang normal. 


\section{Hasil Uji Multikolinearitas}

Hasil yang didapat dalam uji multikolinearitas adalah :

Tabel 2

Hasil Uji Multikolinearitas

\begin{tabular}{lccccc}
\hline \multicolumn{1}{c}{$\begin{array}{c}\text { Variabel } \\
\text { Independen }\end{array}$} & $\begin{array}{c}\text { Toleranc } \\
\mathrm{e}\end{array}$ & Std & VIF & Std & Keterangan \\
\hline Kualitas & 0,681 & $>0.10$ & 1.46 & $<10$ & TidakAda \\
pelayanan & & & 9 & & Multikolinearitas \\
Citra merk & 0,783 & $>0.10$ & $\begin{array}{c}1.27 \\
\text { Tidak Ada }\end{array}$ & $<10$ & $\begin{array}{c}\text { Multikolinearitas } \\
\text { Kepercayaan }\end{array}$ \\
& 0,631 & $>0.10$ & 1.58 & $<10$ & $\begin{array}{c}\text { Tidak Ada } \\
\text { Multikolinearitas }\end{array}$ \\
\hline
\end{tabular}

Berdasarkan tabel diatas menunjukkan tidak terjadi multikonearitas karena nilai tolerance value $>0,10$ dan nilai VIF $<10$.maka dapat disimpulkan bahwa tidak terdapat multikolinearitas.

\section{Hasil Uji Heteroskedastisitas}

Hasil yang didapat dalam uji heteroskedastisitas adalah :

Tabel 3

Uji Heteroskedastisitas

\begin{tabular}{lcc}
\hline \multicolumn{1}{c}{ Model } & Sig. & Keterangan \\
\hline $\begin{array}{l}\text { Kualitas } \\
\text { pelayanan }\end{array}$ & 0,335 & $\begin{array}{c}\text { Tidak Ada } \\
\text { Heteroskedastisitas } \\
\text { Citra merk }\end{array}$ \\
$\begin{array}{l}\text { Tidak Ada } \\
\text { Kepercayaan }\end{array}$ & 0,825 & $\begin{array}{c}\text { Heteroskedastisitas } \\
\text { Tidak Ada } \\
\text { Heteroskedastisitas }\end{array}$ \\
\hline
\end{tabular}

Hasil output perhitungan uji Heteroskedasitas menggunakan uji Glejsermenunjukkan probability value sebesar untuk variabel kualitas pelayanan sebesar 0,335, Citra merk sebesar 0,825, Kepercayaansebesar 0,541, semua p-value > 0,05 ini berarti model regresi yang digunakan tidak terjadi heteroskedasitas. 


\section{Hasil Uji Regresi Linier Berganda}

Nilai a dan b1, b2, b3 dalam uji regresi linear berganda adalah:

Tabel 4

Analisis Regresi Linear Berganda

\begin{tabular}{lcc}
\hline Model & \multicolumn{2}{c}{$\begin{array}{c}\text { Unstandardized } \\
\text { Coefficients }\end{array}$} \\
& $B$ & Std. Error \\
\hline (Constant) & 1.538 & 1.862 \\
Store Atmosphere & 0,171 & 0,085 \\
Service Excellent & 0,463 & 0,068 \\
Celebrity Endorser & 0,288 & 0,099 \\
\hline
\end{tabular}

Berdasarkan tabel diatas persamaanya adalah :

$\mathrm{Y}=1.538+0,171 \mathrm{X} 1+0,463 \mathrm{X} 2+0,288 \mathrm{X} 3+\mathrm{e}$

\section{Uji F}

Hasil dari nilai $\mathrm{F}_{\text {hitung }}$ sebagai berikut:

Tabel 5

Hasil Uji F

\begin{tabular}{lccc}
\hline Model & $\mathrm{F}$ & Sig. & Keterangan \\
\hline Regression & 42.512 & $000^{\mathrm{b}}$ & $\mathrm{H}_{1}$ diterima \\
& & & $\mathrm{H}_{0}$ ditolak \\
$\begin{array}{l}\text { Residual } \\
\text { Total }\end{array}$ & & & \\
\hline
\end{tabular}

$F_{\text {hitung }}$ sebesar 42.512> $F_{\text {tabel }}$ dengan tingkat signifikan sebesar 0,000 atau < 0,05 Dapat disimpulkan bahwa $\mathrm{H}_{0}$ ditolak karena kualitas pelayanan, Citra merk dan Kepercayaan terdapat pengaruh simultan terhadap kepuasan konsumen. 


\section{Uji t}

Hasil dari Uji t adalah:

\section{Tabel 6}

Hasil Uji T

\begin{tabular}{lcccc}
\hline Model & $\mathrm{B}$ & $\mathrm{T}$ & Sig. & Keterangan \\
\hline (constant) & 1.538 & 0,826 & 0,411 & \\
$\begin{array}{l}\text { Kualitas } \\
\text { pelayanan }\end{array}$ & 0,171 & 2.019 & 0,046 & $\mathrm{H}_{2}$ ditolak \\
$\begin{array}{l}\text { Citra merk } \\
\text { Kepercayaan }\end{array}$ & 0,463 & 6.831 & 0,000 & $\mathrm{H}_{3}$ diterima \\
& 0,288 & 2.906 & 0,005 & $\mathrm{H}_{4}$ diterima
\end{tabular}

Pada variabel kualitas pelayanan probability value sebesar $0,046<0,05$ maka $\mathrm{H}_{2}$ diterima berarti ada pengaruh yang positif dan signifikan terhadap kepuasan konsumen di Universitas Islam Batik Surakarta.

Pada variabel citra merk probability value sebesar 0,000<0,05 maka $\mathrm{H}_{3}$ diterima berarti ada pengaruh yang positif dan signifikan terhadap kepuasan konsumen di Universitas Islam Batik Surakarta.

Dan pada variabel kepercayaan probability value sebesar $0,005<0,05$ maka Ho diterima berarti ada pengaruh yang positif dan signifikan terhadap kepuasan konsumen di Universitas Islam Batik Surakarta.

\section{Koefisien Determinasi}

Hasil perhitungan nilai adjusted $R$ square adalah:

\section{Tabel 7}

Hasil Koefisien Determinasi

\begin{tabular}{ccc}
\hline$R$ & $R$ Square & Adjusted $R$ Square \\
\hline $0,752^{\mathrm{a}}$ & 0,565 & 0,552 \\
\hline
\end{tabular}

Nilai adjusted $\mathrm{R}$ square $=0$,552dapat disimpulkan bahwa pengaruh variabel kualitas pelayanan, Citra merk dan kepercayaan terhadap variabel terikat kepuasan konsumen di Universitas Islam Batik Surakarta.Sebesar 55,2\% sedangkan sisanya $(100 \%-55,2 \%)=44,8 \%$ dipengaruhi oleh faktor-faktor lain diluar variabel yang sudah diteliti. 


\section{Pembahasan}

Berdasarkan penelitian ini, dapat dibuktikan bahwa uji $\mathrm{F}$ diterima secara simultan dengan variabel kualitas pelayanan, Citra merk dan kepercayaan terhadap kepuas an konsumen.

Berdasarkan hasil penelitian dari uji $\mathrm{t}$ bahwa variabel kualitas pelayanan berpengaruh terhadap variabel terikat yaitu kepuasan konsumen dengan hasil probability ebesar 0,046>0,05 Hasil ini juga mendukung penelitian (Anggraeni dan Karmilasari, 2017) Menjelaskan bahwa hasil yang dianalisi berpengaruh positif dan signifikan terhadap pengguna jasa Go-jek di Universitas Islam Batik Surakarta.

Berdasarkan penelitian analisis dari uji $\mathrm{t}$ menunjukkan bahwa variabel citra merk berpengaruh positif dan signifikan terhadap kepuasan onsumen serta simultan dengan memperoleh hasil probability sebesar 0,000<0,05 Hasil ini juga didukung oleh penelitian (Rizan, Yulianti dan Rahmi, 2015). Menjelaskan bahwa hasil yang dianalisi berpengaruh positif dan signifikan terhadap pengguna jasa Go-jek di Universitas Islam Batik Surakarta.

Berdasarkan hasil analisis dari uji t menunjukkan bahwa variabel kepercayaan berpengaruh dan signifikan terhadap kepuasan konsumen di Universitas Islam Batik Surakarta dengan hasil probability sebesar 0,005<0,05. Hasil ini juga diperkuat oleh (Wijaya dan Kempa, 2018) Menjelaskan bahwa hasil yang dianalisi berpengaruh positif dan signifikan terhadap pengguna jasa Go-jek di Universitas Islam Batik Surakarta.

\section{KESIMPULAN}

1) Kualitas pelayanan berpengaruh positif dan signifikan terhadap kepuasan konsumen di Universitas Islam Batik Surakarta.

2) Citra merk berpengaruh positif dan signifikan terhadap kepuasan konsumen di Universitas Islam Batik Surakarta.

3) Kepercayaan berpengaruh positif dan signifikan terhadap kepuasan konsumen di Universitas Islam Batik Surakarta.

\section{Saran}

Berdasarkan hasil kesimpulan di atas, maka saran yang peneliti sampaikan kaitanya dengan kepuasan konsumen adalah sebagai berikut :

1) Hendaknya perusahaan Go-jek meningkatkan kualitas pelayananya agar konsumen mendapatkan kepuasan yang diharapkan dan dibutuhkan konsumen, semoga ojek online mampu memberikan pilihan alternative di bidang transpotasi.Perusahaan Go-jek harus lebih meningkatkan citra merk perusahaan dengan melalui promosi di website dan memasang iklan dijalanan agar konsumen tahu bahwa gojek itu mempunya kualitas pelayanan yang bagus dengan fitur-fitur yang diberikan kepada masyarakat.

2) Hendaknya perusahaan Go-jek lebih meningkatkan kepercayaan mengenai produk atau jasa yang ditawahkan kepada konsumen, misalnya melalui penjelasan lengkap mengenai proses pembelian sampai proses penjemputan dan pengiriman barang.

3) Bagi peneliti selanjutnya sebagai bahan referensi dalam melakukan penelitian yang berkaitan tentang kualitas pelayanan, citra merk dan kepercayaan terhadap kepuasan 
konsumen. dalam penelitian berikutnya agar bisa lebih dikembangkan lagi dengan mengkombinasi variabel yang terdapat dalam penelitian ini dengan variabel lain, dengan menggunakan item pertanyaan koesioner yang berbeda.

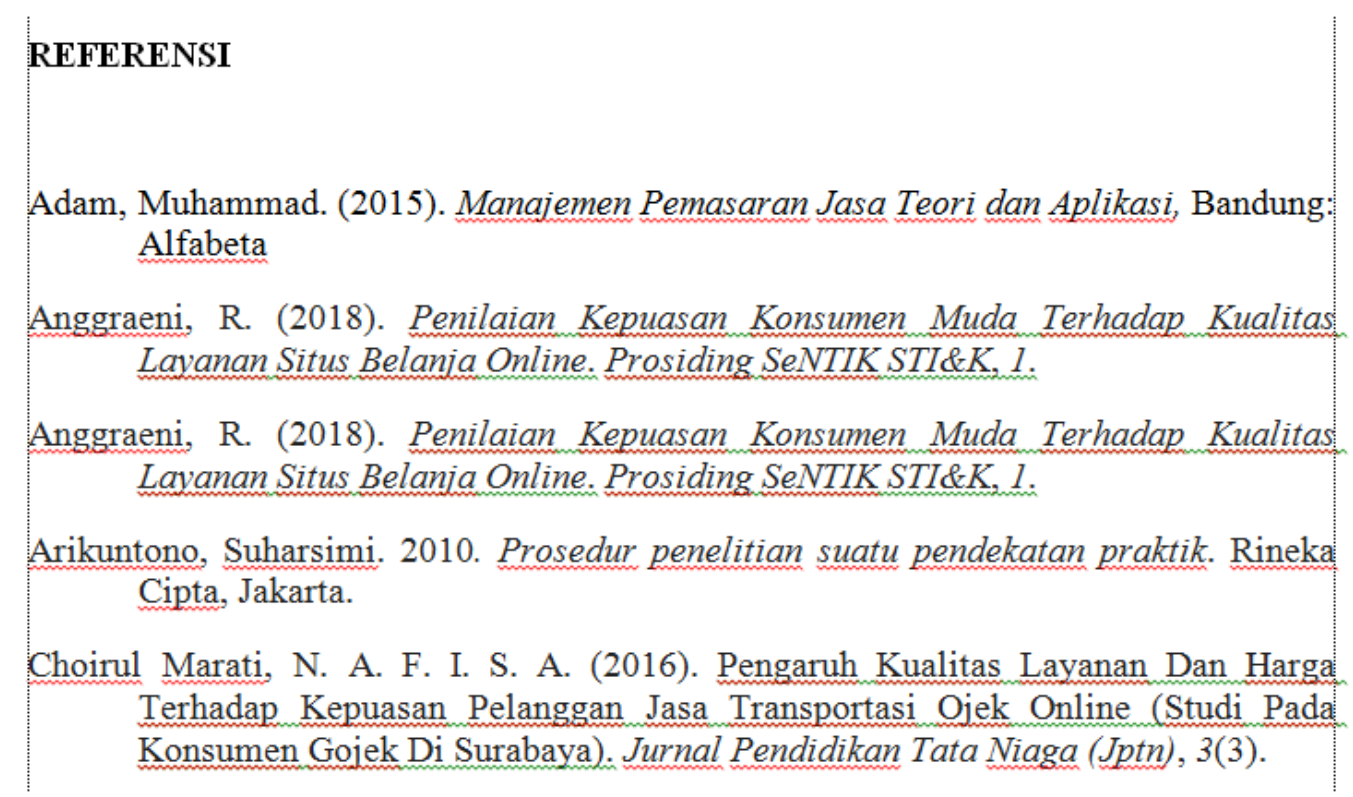

Kiswara, a. e. p. (2017). analisis kualitas layanan, kepuasan pelanggan, kepercayaan, komitmen dan loyalitas pelanggan pada layanan e-commerce (studi pada pelanggan layanan traveloka) (doctoral dissertation, fe umy).

Kotler, p. dan Kevin 1.k. (2016). Manajemen pemasaran edisi 12 jilid 1 \& 2. Jakarta pt.indeks

Kotler, P.,\& Keller, K. L.(2009). Manajemen Pemasaran, (EdisiKetigaBelas, JilidDua) Jakarta : Erlangga

Lovelock, C, dan Wirtz, J. 2011. Pemasaran Jasa Perspektif E7. Erlangga, Jakarta.

Rizan, M., Yulianti, D., \& Rahmi, R. (2015). The Influence Of Price And Service Quality Of Brand Image And Its Impact On Customer Satisfaction Gojeh (Students Study On A State University Of Jakarta). Jrmsi-Jurnal Riset Manajemen Sains Indonesia, 6(2), 639-658.

Rizan, M., Yulianti, D., \& Rahmi, R. (2015). The Influence Of Price And Service Quality Of Brand Image And Its Impact On Customer Satisfaction Gojeh (Students Study On A State University Of Jakarta). Jrmsi-Jurnal Riset Manajemen Sains Indonesia, 6(2), 639-658.

Suharyono, S., \& Yulianto, E. (2017). Pengaruh Bauran Promosi Keputusan Pembelian Dan Kepuasan Pelanggan (Survei Pada Mahasiswa Binus University Yang Menggunakan Jasa Go-jek Di Jakarta). Jurnal Administrasi Bisnis, 46(2), 37-45. 
Tijptono, Fandy. 2011. Seri Manajemen merek 01-Manajemen \& Strategi Merk. Yogyakarta: Andy Offset.

Turban, E. David King. Jae Lee. Ting-Peng.And Decorrah C. Turban 2010.Elecronic commerce. Managerial perspective Global. Edition (6 edistion). New Jersey: Pearson.

Wijaya, c. (2018). pengaruh kepercavaan, kemudahan, kualitas informasi terhadap kepuasan konsumen melalui keputusan pembelian produk fashion di lazada. agora, 6(2).

Wijaya, c. (2018). pengaruh kepercayaan, kemudahan, kualitas informasi terhadap kepuasan konsumen melalui keputusan pembelian produk fashion $d t$ lazada. agora, 6(2). 